\title{
Eating behaviors among female adolescents in Kuantan District, Pahang, Malaysia.
}

\begin{abstract}
This study examined eating behaviors among female adolescents. A total of 407 female students aged between 13-19 years were randomly selected from two secondary schools in Kuantan district, Pahang, Malaysia. All participants were required to complete a selfadministered Eating Behaviors Questionnaire and their weight and height were measured by the researchers. A majority of the participants were Malays $(65.3 \%)$, followed by Chinese $(28.3 \%)$ and Indians $(6.4 \%)$. There were $5.9 \%$ underweight participant, $75.4 \%$ were normalweight and $18.7 \%$ were overweight. About one third (35.9\%) never skipped any of the daily three meals, but another half $(52.6 \%)$ skipped at least one meal a day and the remaining $(11.5 \%)$ had even skipped all three meals in a day. The most frequently missed meals were breakfast (47.4\%). Half (51.4\%) snacked between meals daily and three in four $(76.9 \%)$ had their meals with family members. No differences were found between the socio-demographic variables (age, household members, parent's total year of schooling, parental monthly income and living arrangement) and meal skipping behaviors. However, those who usually skipped meals were those who usually eat alone $(\mathrm{Chi} 2=16.933$, $\mathrm{p}<0.0001)$, overweight $(\mathrm{Chi} 2=$ 15.943, $\mathrm{p}<0.05)$ and were Malays (Chi2 $=33.827, \mathrm{p}<0.05)$. In conclusion, meal skipping, snacking and practicing various weight loss behaviors were some of the unhealthy eating behavior depicted among adolescent girls. Focusing on promotion of healthy eating that stressed on the importance of regular intakes of main meals during adolescence is crucial for their current and future health and well-being.
\end{abstract}

Keyword: Adolescents; Snacking; Meal skipping; Breakfast; Malaysia. 